\title{
Modifying Polyacrylamide Background Color for the Nitroblue Tetrazolium-Based Superoxide Dismutase Staining Assay
}

\author{
Robert Louis Bertrand, Michael Okechukwu Eze* \\ Department of Chemistry, University of Winnipeg, Winnipeg, Canada \\ Email: ${ }^{*}$ m.eze@uwinnipeg.ca
}

Received 12 February 2014; revised 20 March 2014; accepted 30 March 2014

Copyright (C) 2014 by authors and Scientific Research Publishing Inc.

This work is licensed under the Creative Commons Attribution International License (CC BY).

http://creativecommons.org/licenses/by/4.0/

(c) (i) Open Access

\section{Abstract}

The reduction of nitroblue tetrazolium by superoxide radicals generated from photo-reactive riboflavin has been in use for more than four decades to detect superoxide dismutase (SOD) on nondenaturing polyacrylamide gels. SOD research in medicine and biochemistry has warranted the development of multiple assay variants to overcome specific experimental constraints or to combine the SOD assay with other enzyme assays. Fine-tuning reagent concentrations to effectively visualize bands continue to be a major research obstacle in assay development. Herein we describe a straightforward technique to reliably adjust the background color of polyacrylamide gels without compromising assay efficacy. Low micromolar to low millimolar concentrations of yellow riboflavin can be mixed with the blue of reduced nitroblue tetrazolium to controllably produce blue, purple, yellow-brown, or yellow gel backgrounds. The advantage of this technique is that the assay is not modified by the introduction of new reagents. Quantitative reliability of these alternative stains was assessed by plotting determined band intensity values against known enzyme loads. The correlation $\left(\mathrm{R}^{2}\right)$ values of trial averages were compared against the average correlation of the standard $0.028 \mathrm{mM}$ riboflavin solution using pooled standard deviation and Student's T-test at $\mathbf{9 5 \%}$ confidence. Assay sensitivity was assessed by comparing lowest possible visible enzyme load of the experimental stains with the $0.028 \mathrm{mM}$ riboflavin standard. No difference in the quantitative reliability was found in any riboflavin concentration. The minimum reliable sensitivity of the assay was found to be $\mathbf{1 0} \mathbf{n g}$ for each concentration of riboflavin. This technique has already been employed to analyze SOD protein expression levels in extracts of Escherichia coli (Bertrand et al., Med Hypotheses 2012; 78:130-133, 2012; Bertrand \& Eze, Adv. Enz. Res., 1: 132-141, 2013).

\section{Keywords}

Superoxide Dismutase, Riboflavin, Gel Electrophoresis, Assays

\footnotetext{
${ }^{*}$ Corresponding author.
} 


\section{Introduction}

Superoxide dismutase (SOD) is the antioxidant enzyme responsible for eliminating superoxide radicals, ubiquitous in nearly all forms of life. SOD is essential for mitigating cellular oxidative damage: Its absence or abnormal expression has been associated with multiple severe pathologies, including neonatal cardiomyopathy [1], hepatocellular carcinoma [2], age-associated muscular atrophy [3], amyotrophic lateral sclerosis [4], down syndrome [5], hypertension [6], acute respiratory distress syndrome (ARDS) [7], and chronic obstructive pulmonary disease (COPD) [8]. The medical and biochemical relevance of SOD has thus warranted the development of multiple enzyme assays over the decades. The nitroblue tetrazolium (NBT)—based SOD assay, originally developed by Beauchamp and Fridovich in 1971 [9], operates through the reduction of NBT by superoxide radicals generated by photo-reactive riboflavin. As SOD efficiently removes superoxide, achromatic bands form on a uniformly blue background when the technique is applied to non-denaturing polyacrylamide gels. There have since been published multiple variations of this assay in response to specific experimental requirements. For example, some variations employ a lower concentration of NBT [10] [11] this study] because the original concentration prescribed [9] would be prohibitively expensive for routine analysis and with larger staining solutions. Another variation of the NBT-based assay includes an assay for the simultaneous detection of catalase on the same gel [10]. Other variations include modest changes in the riboflavin concentration [12], inclusion of ethylenediaminetetraacetate (EDTA) [11] (which promotes superoxide generation via the light-dependent reduction of free flavins and by chelating trace metals that inhibit superoxide generation [13] [14]), and a simplified methodology that combines NBT and riboflavin application together as a single solution [11]. A significant research obstacle in the development of these assays is the extensive fine-tuning of reagents required to achieve effective band-background contrast and/or to visualize multiple enzymes (e.g., See reference [10]). A straightforward technique for changing the background color for enzyme visualization would therefore be advantageous to assay developers.

We have observed that the background color of non-denaturing polyacrylamide gels during staining can be changed to a variety of colors by exploiting the natural yellow color of riboflavin. This yellow superoxide donor mixes with the blue of NBT to produce green. In lesser concentrations this will darken the background to blue or purple. Alternatively, higher concentrations of riboflavin can be employed to overpower the darkening effect to produce a brilliant yellow background. The accuracy of quantification and the minimum sensitivity were not found to be affected within the range examined (0.028 - 33.22 $\mathrm{mM}$ riboflavin). The advantage to this simple technique is that it does not introduce new reagents to the staining solution, simplifying quality control testing during development of future SOD assay variants or refinement of existing ones. Unlike NBT, riboflavin is an inexpensive reagent that can be used liberally or sparsely as needed to achieve effective contrast. Hence, modifying riboflavin concentration is an economical means of exploiting the natural colors of riboflavin and NBT. Both high- and low-riboflavin variants of this assay have already been applied experimentally to elucidate SOD protein expression levels in Escherichia coli, and all three isozymes of E. coli SOD (iron, manganese, and copper-zinc isoforms) were detectable on polyacrylamide gels [15] [16].

\section{Methods}

\subsection{Materials and Methods}

Five, 10, 20, 40, and 80 nanograms of E. coli SOD (Sigma-Aldrich; St. Louis, MO, USA) were electrophoresed in $7.5 \%$ polyacrylamide gels, and then assayed by the methods of Britigan and colleagues [11] with exception to the concentration of riboflavin, as described: A $50 \mathrm{mM}$ phosphate buffer solution ( $\mathrm{pH} 7.8$ ) containing $0.25 \mathrm{mM}$ NBT, 1 mM EDTA, $28 \mathrm{mM}$ tetramethylethylenediamine (TEMED), and $0.028-33.22 \mathrm{mM}$ of riboflavin was applied to gels in darkness for 45 minutes, stirring occasionally, followed by destaining in darkness with phosphate buffer for 45 minutes. Gels were developed by illumination with fluorescent room lighting, photographed with a white overlay, and the bands quantified with a gel analyzer (RaminVakili, Vakili Gel Analysis Unit, Dept. of Chem., University of Winnipeg). A stain containing $0.028 \mathrm{mM}$ riboflavin, the original concentration prescribed by Beauchamp and Fridovich [9], was used throughout as a standard solution.

\subsection{Statistical Analysis and Interpretation}

Quantitative accuracy was assessed by plotting band intensity values against known quantities of SOD. The 
correlation $\left(\mathrm{R}^{2}\right)$ values were then determined as an average of three or four replications for each riboflavin concentration examined (33.22, 4.15, $0.52 \mathrm{mM}$ ), and challenged against a $0.028 \mathrm{mM}$ average via pooled standard deviation and Student's T-test at 95\% confidence. To mitigate the influence of random error on results, the same five protein preparations were used throughout all trials. Thus, any deviation from perfect linearity in the original preparation would be common to all trials; and therefore, differences between data sets would more greatly reflect the inherent effects of each riboflavin stain on quantitation (if any). Whether riboflavin affected assay sensitivity was assessed by comparing the minimum reliably detectable and measurable enzyme load of the three experimental concentrations with the $0.028 \mathrm{mM}$ standard.

\section{Results and Discussion}

All concentrations of riboflavin examined were equally capable of accurately presenting enzyme loads for quantitation (Table 1). There was no change in minimum quantifiable enzyme load from the $0.028 \mathrm{mM}$ standard, which was determined to be $10 \mathrm{ng}$ of SOD throughout (Figure 1). Five nanograms of SOD can be seen in some staining applications, but is unreliably detectable and quantifiable at all concentrations of riboflavin tested, including the $0.028 \mathrm{mM}$ standard. Five nanogram SOD loads were thus omitted from calculations. It is remarkable that the minimum reliable sensitivity obtained in the present study (10 $\mathrm{ng})$ is somewhat better than $16 \mathrm{ng}$ originally reported by Beauchamp and Fridovich [9]. These results demonstrate that even dramatic changes in riboflavin concentration do not affect assay sensitivity or band quantitation.

We have observed that as riboflavin concentration increases, the development time decreased: $33.22 \mathrm{mM}$ of riboflavin required 10 - $15 \mathrm{~min}$., $0.028 \mathrm{mM}$ riboflavin required 30 - $60 \mathrm{~min}$., and 4.15 and $0.52 \mathrm{mM}$ solutions required an intermediate period of time. The time required to develop the standard $0.028 \mathrm{mM}$ applications differs greatly from those reported by other authors, which is usually around 5 to $15 \mathrm{~min}$. [9] [10]. This discrepancy is explainable by their reliance on direct intense light sources to enhance the rate of the light-activated reaction,

Table 1. Average correlates $\left(\mathrm{R}^{2}\right)$ of SOD activity bands.

\begin{tabular}{ccccc}
\hline Riboflavin $(\mathrm{mM})$ & No. of trials & Average Corr. $\left(\mathrm{R}^{2}\right)$ & Standard dev. (s) & Significance (95\%) \\
\hline 33.22 & 3 & 0.9967 & $3.35 \times 10^{-3}$ & None \\
4.15 & 3 & 0.9993 & $9.74 \times 10^{-4}$ & None \\
0.52 & 4 & 0.9976 & $1.37 \times 10^{-3}$ & None \\
0.028 & 4 & 0.9986 & $1.28 \times 10^{-3}$ & N/A \\
\hline
\end{tabular}

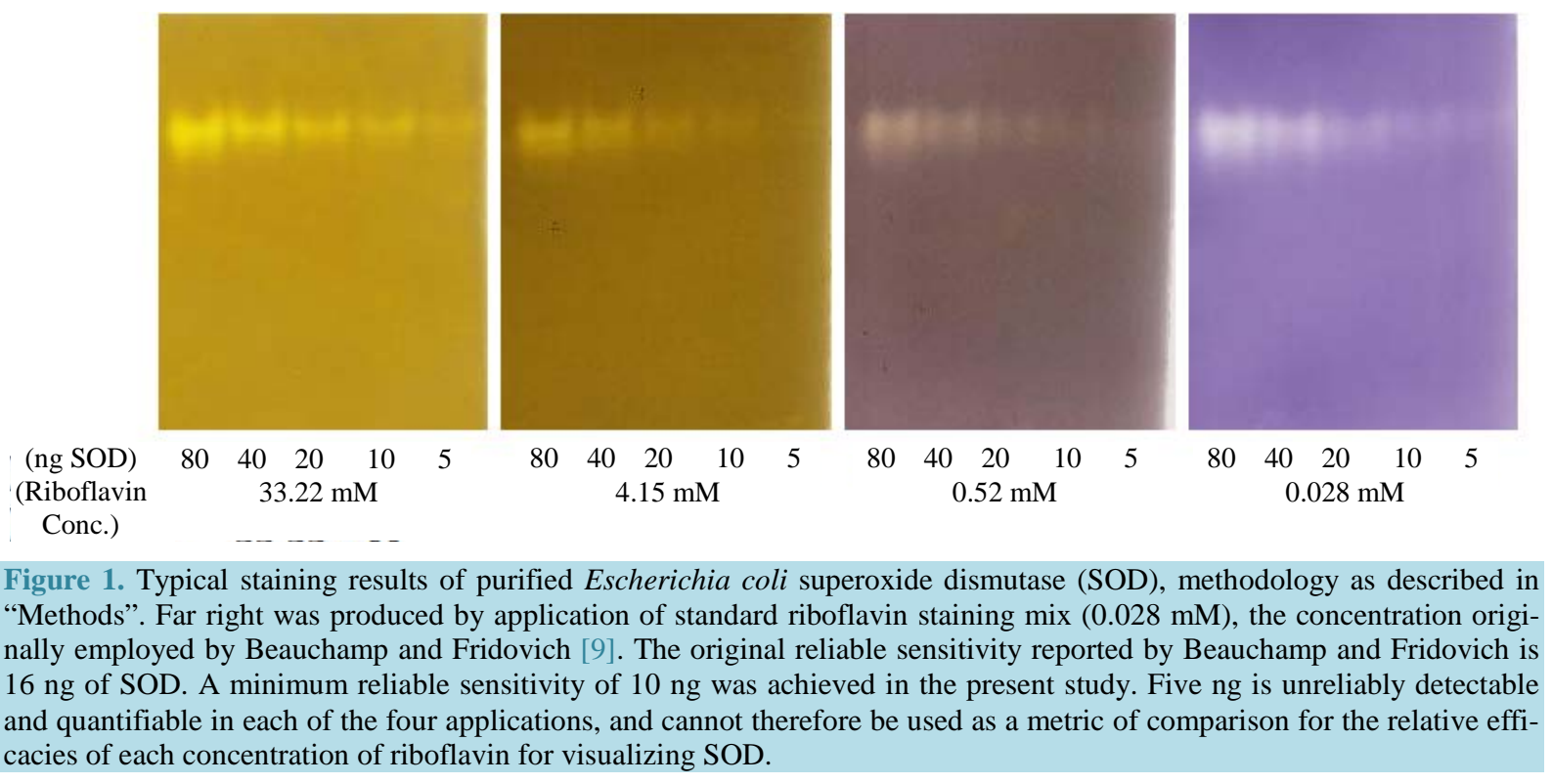


as opposed to fluorescent room lighting used in the present study. Bands produced by highly concentrated applications of riboflavin have the tendency to fade after $30 \mathrm{~min}$., and for this reason it is recommended that regular room lighting be used during development to provide economy of time and effort. It is worthy to note that, regardless of the riboflavin concentration used, as gels develop under light, they darken. By slowing the reaction down with indirect light sources, the researcher is enabled to take multiple photographs at a range of color shades throughout development, and choose the photo with the best band presentation. We have personally found that relying on room lighting alone is better for generating high quality photos suitable for publication. It is equally notable that despite the poor aqueous solubility of riboflavin $(0.225 \mathrm{mM})$, even colloidal solutions of riboflavin (e.g., $33.22 \mathrm{mM}$ ) were capable of staining gels uniformly and reliably. As the quantity of riboflavin is the only changing variable within each staining application, the variance in color seen in the gel backgrounds must be caused by changes in the quantity of riboflavin employed (Figure 1). It appears, therefore, that the modest solubility of riboflavin does not limit the possible colors produced. It is advised that gels stained with such copious riboflavin be briefly rinsed before being allowed to sit in destaining solution.

\section{Conclusion}

We have demonstrated that by changing the quantity of riboflavin used in the staining solution of the superoxide dismutase assay, one can adjust the background color of the polyacrylamide gel. No new reagents were introduced in order to achieve this effect. Statistical analysis showed that changing the riboflavin concentration does not compromise the reliability of quantitation of superoxide dismutase (Table 1). The minimum reliable sensitivity was shown in all applications, including the $0.028 \mathrm{mM}$ riboflavin application originally used by Beauchamp and Fridovich [9], to be 10 ng of superoxide dismutase (Figure 1), consistent with 16 ng originally reported by the authors [9]. Five nanograms of SOD were unreliably detectable and quantifiable. Continued research on superoxide dismutase requires the development of variants of this assay in order to overcome experimental constraints or to combine the assay with other enzyme assays for simultaneous visualization of more than one enzyme. This technique will simplify the fine-tuning of reagent concentrations in order to visualize SOD activity bands fortuitous for assay development.

\section{Acknowledgements}

This work was supported by the following grants which are hereby gratefully acknowledged: Research Corporation Cottrell College Science Award \#5926 [Research Corporation, 4703 E. Camp Lowell Drive, Suite 201, Tucson, AZ 85712, USA] to MOE; two University of Winnipeg (UofW) Major Research Grants \#7437 and \#7671 to MOE; and a Special Grant from the UofW Research and Graduate Studies Office to Dr. Desiree Vanderwel (Chemistry Dept. UofW) and MOE. Funding awarded to RLB from the National Sciences and Engineering Research Council of Canada (NSERC) is also gratefully acknowledged (PGS-M 425305-2012). We are grateful to Mr. RaminVakili (Chemistry Dept., UofW) and Dr. Jamie Galka (Chemistry Dept., UofW) for valuable technical assistance. We are also grateful for constructive commentary provided by anonymous reviewers during earlier drafts of the manuscript.

\section{References}

[1] Li, Y., Huang, T.T., Carlson, E.J., Melov, S., Ursell, P.C., Olson, J.L., Noble, J.L., Yoshimura, M.P., Berger, C., Chan, P.H., Wallace, D.C. and Epstein, C.J. (1995) Dilated Cardiomyopathy and Neonatal Lethality in Mutant Mice Lacking Manganese Superoxide Dismutase. Nature Genetics, 11, 376-381. http://dx.doi.org/10.1038/ng1295-376

[2] Elchuri, S., Oberley, T.D., Qi, W., Eisenstein, R.S., Jackson Roberts, L., Van Remmen, H., Epstein, C.J. and Huang, T.T. (2005) CuZnSOD Deficiency Leads to Persistent and Widespread Oxidative Damage and Hepatocarcinogenesis Later in Life. Oncogene, 24, 367-380. http://dx.doi.org/10.1038/sj.onc.1208207

[3] Muller, F.L., Song, W., Liu, Y., Chaudhuri, A., Pieke-Dahl, S., Strong, R., Huang, T.T., Epstein, C.J., Roberts 2nd, L.J., Csete, M., Faulkner, J.A. and Van Remmen, H. (2006) Absence of CuZn Superoxide Dismutase Leads to Elevated Oxidative Stress and Acceleration of Age-Dependent Skeletal Muscle Atrophy. Free Radicals Biology \& Medicine, 40, 1993-2004. http://dx.doi.org/10.1016/j.freeradbiomed.2006.01.036

[4] Deng, H-X., Hentati, A., Tainer, J.A., Iqbal, Z., Cayabyab, A., Hung, W-Y., Getzoff, E.D., Hu, P., Herzfeldt, B., Roos, R.P., Warner, C., Deng, G., Soriano, E., Smyth, C., Parge, H.E., Ahmed, A., Roses, A.D., Hallewell, R.A., PericakVance, M.A. and Siddique, T. (1993) Amyotrophic Lateral Sclerosis and Structural Defects in Cu, Zn Superoxide Dis- 
mutase. Science, 261, 1047-1051. http://dx.doi.org/10.1126/science.8351519

[5] Groner, Y., Elroy-Stein, O., Avraham, K.B., Schickler, M., Knobler, H., Minc-Golomb, D., Bar-Peled, O., Yarom, R. and Rotshenker, S. (1994) Cell Damage by Excess CuZnSOD and Down Syndrome. Biomedicine \& Pharmacotherapy, 48, 231-240. http://dx.doi.org/10.1016/0753-3322(94)90138-4

[6] Gongora, M.C., Qin, Z., Laude, K., Kim, H.W., McCann, L., Folz, J.R., Dikalov, S., Fukai, T. and Harrison, D.G. (2006) Role of Extracellular Superoxide Dismutase in Hypertension. Hypertension, 48, 473-481. http://dx.doi.org/10.1161/01.HYP.0000235682.47673.ab

[7] Gongora, M.C., Lob, H.E., Landmesser, U., Guzik, T.J., Martin, W.D., Ozumi, K., Wall, S.M., Wilson, D.S., Murthy, N., Gravanis, M., Fukai, T. and Harrison, D.G. (2008) Loss of Extracellular Superoxide Dismutase Leads to Acute Lung Damage in the Presence of Ambient Air: A Potential Mechanism Underlying Adult Respiratory Distress Syndrome. American Journal of Pathology, 173, 915-926. http://dx.doi.org/10.2353/ajpath.2008.080119

[8] Young, R.P., Hopkins, R., Black, P.N., Eddy, C., Wu, L., Gamble, G.D., Mills, G.D., Garrett, J.E., Eaton, T.E. and Rees, M.I. (2006) Functional Variants of Antioxidant Genes in Smokers with COPD and in Those with Normal Lung Function. Thorax, 61, 394-399. http://dx.doi.org/10.1136/thx.2005.048512

[9] Beauchamp, C. and Fridovich, I. (1971) Superoxide Dismutase: Improved Assays and an Assay Applicable to Acrylamide Gels. Analytical Biochemistry, 44, 276-287. http://dx.doi.org/10.1016/0003-2697(71)90370-8

[10] Shukla, M.R., Yadav, R. and Desai, A. (2009) Catalase and Superoxide Dismutase Double Staining Zymogram Technique for Deinococcus and Kocuria Species Exposed to Multiple Stresses. Journal of Basic Microbiology, 49, 593-597. http://dx.doi.org/10.1002/jobm.200900037

[11] Britigan, B.E., Miller, R.A., Hassett, D.J., Pfaller, M.A., McCormick, M.L. and Rasmussen, G.T. (2001) Antioxidant Enzyme Expression in Clinical Isolates of Pseudomonas aeruginosa: Identification of an Atypical Form of Manganese Superoxide Dismutase. Infection and Immunity, 69, 7396-7401. http://dx.doi.org/10.1128/IAI.69.12.7396-7401.2001

[12] Agbas, A., Hui, D., Wang, X., Tek, V., Zaidi, A. and Michaelis, E.K. (2007) Activation of Brain Calcineurin (Cn) by Cu-Zn Superoxide Dismutase (SOD1) Depends on Direct SOD1-Cn Protein Interactions Occurring in Vitro and in Vivo. Biochemistry Journal, 405, 51-59. http://dx.doi.org/10.1042/BJ20061202

[13] Massey, V., Strickland, S., Mayhew, S.G., Howell, L.G., Engel, P.C., Mathews, R.G., Schuman, M. and Sullivan, P.A. (1969) The Production of Superoxide Anion Radicals in the Reaction of Reduced Flavins and Flavoproteins with Molecular Oxygen. Biochemical and Biophysical Research Communications, 36, 891-897. http://dx.doi.org/10.1016/0006-291X(69)90287-3

[14] Terada, L.S., Leff, J.A., Guidot, D.N., Shibao, G.A. and Repine, J.E. (1990) Metals Inhibit Riboflavin-Catalyzed Generation of Superoxide Anion in Vitro. Inflammation, 14, 217-221. http://dx.doi.org/10.1007/BF00917460

[15] Bertrand, R., Danielson, D., Gong, V., Olynik, B. and Eze, M.O. (2012) Sodium Nitroprusside May Modulate Escherichia coli Antioxidant Enzyme Expression by Interacting with the Ferric Uptake Regulator. Medical Hypotheses, 78, 130-133. http://dx.doi.org/10.1016/j.mehy.2011.10.007

[16] Bertrand, R. and Eze, M.O. (2013) Escherichia coli Superoxide Dismutase Expression Does Not Change in Response to Iron Challenge during Lag Phase: Is the Ferric Uptake Regulator to Blame? Advances in Enzyme Research, 1, 132141. http://dx.doi.org/10.4236/aer.2013.14014 